\title{
Aggregation pheromone compounds of the black larder beetle Dermestes haemorrhoidalis Kuster (Coleoptera: Dermestidae)
}

\author{
Rajasekhara Rao Korada · Frans C. Griepink
}

Received: 1 April 2009/Accepted: 22 June 2009 / Published online: 7 July 2009

(c) The Author(s) 2009. This article is published with open access at Springerlink.com

\begin{abstract}
Gas chromatography with simultaneous flame ionisation and electroantennographic detection (GC-EAD) and gas chromatography with mass spectrometry analysis (GC-MS) of abdominal extracts of adult male Dermestes haemorrhoidalis Kuster (Coleoptera: Dermestidae) revealed the presence of electrophysiologically and behaviourally active compounds to its conspecific males and females. Isopropyl dodecanoate (3), isopropyl (Z)-9-tetradecenoate (5), isopropyl tetradecanoate (6), isopropyl (Z)-9-hexadecenoate (7) and isopropyl hexadecanoate (8) were detected in male abdominal extracts only. Analysis of collected male headspace volatiles revealed the presence of six EAD-active compounds (3), (5), (6) and isopropyl tridecanoate (4) plus two unidentified compounds (1) and (9). Synthetic compounds (3), (4), (5), (6) and (7) showed EAD activity with antennae of both sexes in contrast to synthetic (8) which showed EAD activity with female antennae only. Male and female antennae of $D$. haemorrhoidalis reacted with high receptor potentials to isopropyl (Z)-9-dodecenoate (2), although this compound itself was detected in neither male nor female abdominal extracts or headspace volatiles. Petri dish bioassays indicated that male abdominal extracts and
\end{abstract}

R. R. Korada and F. C. Griepink contributed equally to this article.

\section{R. R. Korada}

Regional Centre, Central Tuber Crops Research Institute (Indian Council of Agricultural Research), Dumduma HBC, Bhubaneswar 751019, Orissa, India

e-mail: rajasekhararao.korada@gmail.com

F. C. Griepink $(\bowtie)$

Plant Research International, Wageningen University and Research Centre, P.O. Box 16, 6700 AA Wageningen, The Netherlands

e-mail: frans.griepink@wur.nl compounds (2), (3), (5) and (6) aroused and attracted conspecific male and female beetles significantly $(P<0.05)$ compared to female extracts. These results suggested the presence of a male-produced aggregation pheromone in D. haemorrhoidalis. Field assays with any of the described compounds, however, did not result in attraction of this beetle in significant numbers.

Keywords Dermestes haemorrhoidalis Kuster ·

Dermestidae · Coleoptera-headspace volatiles .

Gas chromatography electroantennographic detection (GC-EAD) · Gas chromatography ·

Mass spectrometry (GC-MS) - Aggregation pheromone

\section{Introduction}

Many of the species belonging to the genus Dermestes are pests in poultry production (Geden and Hogsette 2001), museums (Linnie and Keatinge 2000), Egyptian mummies (Adams 1990; Steffan 1982) and stored cocoons of silkworm Bombyx mori (Sahaf 2007). The black larder beetle, Dermestes haemorrhoidalis Kuster (Coleoptera: Dermestidae) is considered to be an important pest insect infesting Dutch rearing facilities for pet food crickets. Some Dermestid beetles feed directly upon decomposing preferably dried carrion (Schroeder et al. 2002). Dermestid beetles were of significant importance in allergy medicine research (Panzani and Ariano 2001; Ramachandran et al. 1997; Rustin and Munro 1984) and forensic science (Greenberg and Wells 1998; Schroeder et al. 2002; Sukontason et al. 2007). The natural distribution of Dermestid beetles ranges from temperate regions (Sagvolden and Hansen 2001; Jacob and Fleming 1984) to the tropics (Adams 1980; Nair 1986). Dermestid beetles thrive on 
protein-rich media such as carcasses of dead birds and rodents (Cloud and Collison 1986) and were able to tunnel into wooden structures as well as soft thermal insulation materials (Stafford et al. 1988; Axtell and Arends 1990). In contrast to the potential damage they may inflict, these beetles are useful to man when utilised for the rapid decomposition and degradation of dead animals for preservation of their skeletons in museums (Hava and Votruba 2005).

D. haemorrhoidalis tends to aggregate and hide in dark places as does D. maculates De Geer (Rakowski 1988). The aggregation behaviour of $D$. maculatus is mediated by the presence of an aggregation pheromone (Rakowski et al. 1981; Rakowski 1988). The aggregation pheromone is produced by males in the case of D. maculatus (Francke et al. 1979; Levinson et al. 1978, 1981; Shaaya 1981) and D. ater De Geer (Imai et al. 1990). The pheromone source has been identified as an exocrine gland present on the ventral abdomen (Levinson et al. 1978). Feeding adults of D. maculatus utilize a system of both male-produced aggregation pheromone (Levinson and Levinson 1995) and a female-produced sex pheromone (Abdel Kader and Barak 1979). This male-produced pheromone of $D$. maculatus consists of isopropyl (Z)-9-dodecenoate (2), isopropyl (Z)-9-tetradecenoate (5), isopropyl (Z)-9-hexadecenoate (7) and isopropyl (Z)-9-octadecenoate (10) (Fig. 1), of which the first two compounds (2) and (5) elicit high olfactory receptor potentials (off-line) in D. maculatus and provoke a behavioural reaction. The pheromone compounds of D. maculatus have been shown to initiate behavioural response also in other Dermestid species like D. lardarius and $D$. ater (Levinson et al. 1978). Pheromone is thought to be released from the gland but has been found in faecal pellets as well (Rakowski 1988).

Pheromones causing sexual attraction or bisexual aggregation in conspecific species inhabiting food stores can range from one-component messengers to blends of two or more compounds acting jointly on the deutocerebrum of various species (Levinson and Levinson 1995). Ultimately, the success of these compounds or pheromones in field application varies with the procedures involved in collection of volatiles and application in the diverse situations at field level. In this context, we have isolated, identified and synthesized several electrophysiologically and behaviourally active compounds for $D$. haemorrhoidalis from abdominal extracts and headspace volatiles. The identified compounds have been tested in lab and initial field assays for their potential in trapping adult D. haemorrhoidalis beetles.

\section{Materials and methods}

Insects

Adults and grubs of D. haemorrhoidalis were collected from Star Food, Barneveld, The Netherlands, a company producing insects and animal feeds. Insects were kept in cages $(45 \times 45 \times 60 \mathrm{~cm})$ at $24^{\circ} \mathrm{C}$ and $70 \%$ relative humidity and with a photoperiod of 14L:8D. Beetles were collected in glass test tubes, anaesthetized with $0.5 \mathrm{~L} / \mathrm{min}$ $\mathrm{CO}_{2}$ for $10 \mathrm{~s}$ and separated into males and females, based on the sexual dimorphism between male and female beetles. Male beetles have two median exocrine glands, one each on the third and fourth abdominal sternum surrounded by $5-8$ bristles which were absent in females.

\section{Chemicals and standards}

Reference chemicals for this study were synthesized at PHEROBANK laboratories of Plant Research International, Wageningen, The Netherlands. The isopropyl esters were synthesized from the corresponding aldehydes according to Takeda et al. (1997). Aldehydes were dissolved in isopropyl alcohol $(0.3 \mathrm{M})$ and cooled in an ice bath. To this solution slowly one equivalent of $12 \mathrm{M} \mathrm{HCl}$ and consequently one equivalent of $30 \% \mathrm{H}_{2} \mathrm{O}_{2}$ (in water) was added. The cooling bath was removed and the light yellow turbid reaction mixture was stirred overnight after which all starting aldehyde was consumed. The reaction mixture was extracted with ether, washed with $\mathrm{NaHCO}_{3}$, dried over $\mathrm{MgSO}_{4}$, concentrated and purified over silica gel
Fig. 1 Chemical structures of the isopropyl esters discussed; (2) isopropyl (Z)-9dodecenoate, (3) isopropyl dodecanoate, (4) isopropyl tridecanoate, (5) isopropyl (Z)-9-tetradecenoate,

(6) isopropyl tetradecanoate, (7) isopropyl (Z)-

9-hexadecenoate, $(8)$ isopropyl hexadecanoate, (10) isopropyl (Z)-9-octadecenoate

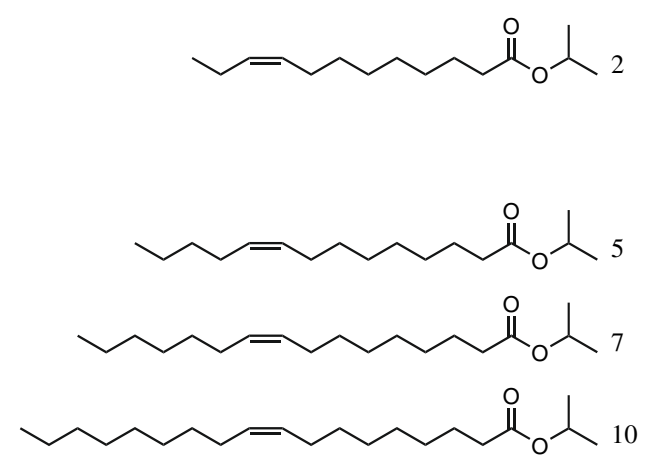


to obtain the desired product in moderate yields $(30-50 \%$ based on the aldehyde).

\section{Insect extracts}

One hundred beetles of each sex were used to make a whole body extract. Insects were anaesthetized as described before and the elytra, wings and legs were removed from the body. The abdomen was separated with dissection scissors and allowed to immerse in $10 \mathrm{ml}$ of redistilled hexane for 1 day. The obtained extract was filtered through Whatman No. 1 paper and concentrated to $1 \mathrm{ml}$ under argon atmosphere. Extract were stored at $-20^{\circ} \mathrm{C}$ prior to use.

\section{Collection of headspace volatiles}

A 6-glass jars parallel volatile collection unit (VCU) fitted in an incubator (Elbanton, Kerkdriel, The Netherlands) was used for beetle headspace volatile collections. One hundred male and female D. haemorrhoidalis beetles were kept separately in $2.5-\mathrm{L}$ glass jars (Rundrand-Glas 100 , WECK 2700) which were fitted in the VCU. Air $(100 \mathrm{ml} / \mathrm{min})$ passed through activated charcoal was released into the jars. The headspace volatiles from the jars were collected onto adsorption tubes (Gerstel TDS 2/A (OD $6.0 \mathrm{~mm}$ ) filled with $100 \mathrm{mg}$ 80/100 mesh SuperQ (Alltech Associates, Inc, Deerfield). Both sides of the tube were fitted with quartz wool (Interscience BV, Breda, The Netherlands). All flows were checked with a Digital Flow Check (Alltech Breda, The Netherlands). Headspace volatiles were collected at 24-h intervals for four consecutive days. Adsorption tubes were changed every day in the morning at 9.00 a.m. and the absorbed volatiles were extracted immediately with $5 \mathrm{ml}$ of redistilled hexane. Extracts were pooled and concentrated under argon to $200 \mu \mathrm{l}$. Adsorption tubes were cleaned with $5 \mathrm{ml}$ of acetone (2 times) and dried at $240^{\circ} \mathrm{C}$ for $30 \mathrm{~min}$ while being purged with purified nitrogen gas $(20 \mathrm{ml} / \mathrm{min})$. Cleaned tubes were reused for volatile collection.

Coupled gas-chromatography electroantennographic detection (GC-EAD)

Antennal responses of male and female D. haemorrhoidalis to collected abdominal extracts and headspace volatiles were studied by gas chromatography with electroantennographic detection (GC-EAD) (Trace GC-2000, Interscience, Breda, The Netherlands) equipped with a cold on-column injector. The GC was equipped with an Alltech 30 m AT-5 (5\% phenyl, 95\% polydimethylsiloxane) fused silica column, $0.25 \mathrm{~mm}$ ID and $0.5 \mu \mathrm{m}$ film thickness or an Alltech AT-aquawax (100\% polyethylene glycol) fused silica column, $0.25 \mathrm{~mm}$ ID and $0.25 \mu \mathrm{m}$ film thickness. Conditions were: carrier gas, helium (constant flow $2.5 \mathrm{ml} / \mathrm{min}$ ); temperature programming: $80^{\circ} \mathrm{C}(0.8 \mathrm{~min}$ hold $)$ to $280^{\circ} \mathrm{C}(10 \mathrm{~min}$ hold $)$ at $10^{\circ} \mathrm{C} / \mathrm{min}$ (AT-5 column), or $50^{\circ} \mathrm{C}$ ( $0.8 \mathrm{~min}$ hold) to $250^{\circ} \mathrm{C}$ (4 min hold) at $10^{\circ} \mathrm{C} / \mathrm{min}$ (AT-aquawax column); detector temperature: $250^{\circ} \mathrm{C}$; the temperature of the transfer line (Syntech Laboratories, Hilversum, The Netherlands) between the GC and EAD followed the oven temperature. The injected sample $(1 \mu \mathrm{l})$ was equally split between a flame ionisation detector (FID) and the electroantennographic detector (EAD). Over the antenna, a flow of purified and humidified air was maintained at a flow rate of $80 \mathrm{~cm} / \mathrm{s}$. Antennae were mounted between two glass electrodes filled with Ringer solution $(6.4 \mathrm{mM} \mathrm{KCl}$, $12 \mathrm{mM} \mathrm{MgCl}_{2} \cdot 6 \mathrm{H}_{2} \mathrm{O}, 9.6 \mathrm{mM} \mathrm{KOH}, 12 \mathrm{mM} \mathrm{NaCl}$, $20 \mathrm{mM} \mathrm{KH} \mathrm{KO}_{4}, 1 \mathrm{mM} \mathrm{CaCl} 2$ and $354 \mathrm{mM}$ glucose in deionised water. The EAD plus peripheral equipment were manufactured by Syntech Laboratories, The Netherlands. Antennae were removed from the insect head with surgical scissors. One-fourth of the distal segment of the antenna was cut with a 1-mm sapphire blade (World Precision Instruments, Inc, Sarasota, USA). To distinguish EAD responses from noise, 10-12 GC-EAD runs were carried out with each sample. Each GC-EAD run was followed by two consecutive cleaning runs $(5 \mu \mathrm{l}$ redistilled hexane injected). Every day $1 \mu \mathrm{l}$ of an alkane mixture $\left(\mathrm{C}_{7}-\mathrm{C}_{27} ; 0.05 \mathrm{mg} / \mathrm{ml}\right)$ was injected to test the system performance and to function as reference for Kovats indices calculations.

Gas chromatography-mass spectrometry (GC-MS) analyses of extracts and headspace volatiles

GC-EAD active compounds were identified by mass spectrometry by injecting the same extracts used for GC-EAD on a GC-MS system under comparable conditions. GC-MS analyses were carried out on a Hewlett Packard 5973 mass selective detector $(70 \mathrm{eV})$ coupled to a Hewlett Packard 6890 gas chromatograph equipped with a split/splitless injector. The gas chromatograph was equipped with an Alltech $30 \mathrm{~m}$ AT-5 fused silica column, $0.25 \mathrm{~mm}$ ID and $0.25 \mu \mathrm{m}$ film thickness or an Alltech $30 \mathrm{~m}$ AT-aquawax fused silica column, $0.25 \mathrm{~mm}$ ID and $0.25 \mu \mathrm{m}$ film thickness run in constant flow mode $(1.3 \mathrm{ml} /$ min helium). Temperature programming: $50^{\circ} \mathrm{C}(2 \mathrm{~min}$ hold) to $300^{\circ} \mathrm{C}\left(20 \mathrm{~min}\right.$ hold) at $15^{\circ} \mathrm{C} / \mathrm{min}$ (AT-5 column) or $50^{\circ} \mathrm{C}(0.8 \mathrm{~min}$ hold $)$ to $250^{\circ} \mathrm{C}(4 \mathrm{~min}$ hold $)$ at $10^{\circ} \mathrm{C} / \mathrm{min}$ (AT-aquawax column); transfer line temperature, $300^{\circ} \mathrm{C}$; injector temperature, $230^{\circ} \mathrm{C}$. One microlitre of extract or concentrated headspace volatiles were injected manually into the GC-MS system for analysis. Injections were done in splitless mode only $(1 \mu \mathrm{l})$. 
Analysis and identification of GC-EAD active peaks

Synthetic standards were mixed with $\mathrm{C}_{7}-\mathrm{C}_{27}$ alkanes and injected into the GC-EAD and GC-MS and chromatograms were overlaid with those of the extracts in order to identify the compounds of interest. MSD Productivity ChemStation software was used for the analysis of compounds in the extracts and headspace volatiles. The compounds of interest were identified using standard and own mass spectral libraries and subsequently confirmed by comparison with authentic synthetic samples.

Dimethyl disulphide (DMDS) derivatisation

The position and configuration of the double bond in the isopropyl esters were determined by derivatisation with DMDS followed by mass spectrometric analysis (Griepink et al. 1996). One millilitre of male D. haemorrhoidalis beetle gland extract (100 beetle equivalent) was concentrated to $20 \mu \mathrm{l}$ under argon and added to $100 \mu \mathrm{l}$ freshly distilled DMDS. To this solution a crystal of iodine was added and the mixture was heated for $2 \mathrm{~h}$ at $60^{\circ} \mathrm{C}$ in an oven. The reaction was subsequently quenched by adding a few drops of aqueous saturated $\mathrm{Na}_{2} \mathrm{~S}_{2} \mathrm{O}_{3}$ (until the red colour of the iodine faded). To the reaction mixture $200 \mu \mathrm{l}$ diethyl ether was added. The organic layer was collected, passed through a small column filled with $\mathrm{NaCl}$ and concentrated to $10 \mu \mathrm{l}$. About $1 \mu \mathrm{l}$ was injected (splitless mode) into the GC-MS for analysis.

\section{Behavioural assays}

A filter paper was put at the bottom of a Petri dish $(15 \mathrm{~cm}$ diameter). Thirty beetles of each sex of $D$. haemorrhoidalis beetles starved for 1 day were released on the filter paper in the Petri dish after which the insects were left for $1 \mathrm{~h}$. In the centre of the Petri dish a 1.5-cm diameter paper disc was placed, impregnated with either $10 \mu \mathrm{l}$ abdominal extract (1 beetle equivalent) or $0.05 \mathrm{mg} / \mathrm{ml}$ synthetic standards $(0.5 \mu \mathrm{g} /$ compound $)$. When the beetles raised their antenna, head and thorax and began to walk, this was considered as an 'arousal responses' (Vick et al. 1970). The behavioural responses were observed and classified into two categories (1) arousal/searching (including preliminary recognition) and (2) physical touching the impregnated paper in the middle of the Petri dish. Behaviour (1) was observed after $30 \mathrm{~s}$ and behaviour (2) was recorded after $30 \mathrm{~min}$. Each test was repeated three times.

Statistical analysis

Response data of male and female beetles was transformed into Arc Sin values. Two-way analysis of variance (ANOVA) followed by Duncan's multiple range test (DMRT) was conducted to compare the means.

\section{Results}

GC-EAD analyses of male abdominal extracts of $D$. haemorrhoidalis revealed three compounds, namely isopropyl dodecanoate (3), isopropyl (Z)-9-tetradecenoate (5) and isopropyl tetradecanoate (6) that provoked a response from male as well as female antennae (Fig. 2), whereas female abdominal extracts did not elicit any electrophysiological response neither in male nor female antennae. In all cases female antennae showed a higher response than did male antennae. Electroantennograms of male and female antennae obtained with male headspace volatiles showed compounds (3), (5) and (6) plus isopropyl tridecanoate (4) as well as two unidentified compounds (1) and (9) (Fig. 3). Again all compounds elicited less receptor potential in males compared to female antennae.

GC-MS analysis of the abdominal extracts revealed compounds (3), (5), (6) plus two related homologues isopropyl (Z)-9-hexadecenoate (7) and isopropyl
Fig. 2 Responses of male and female Dermestes haemorrhoidalis antennae to their conspecific male abdominal extract (AT-5 column)

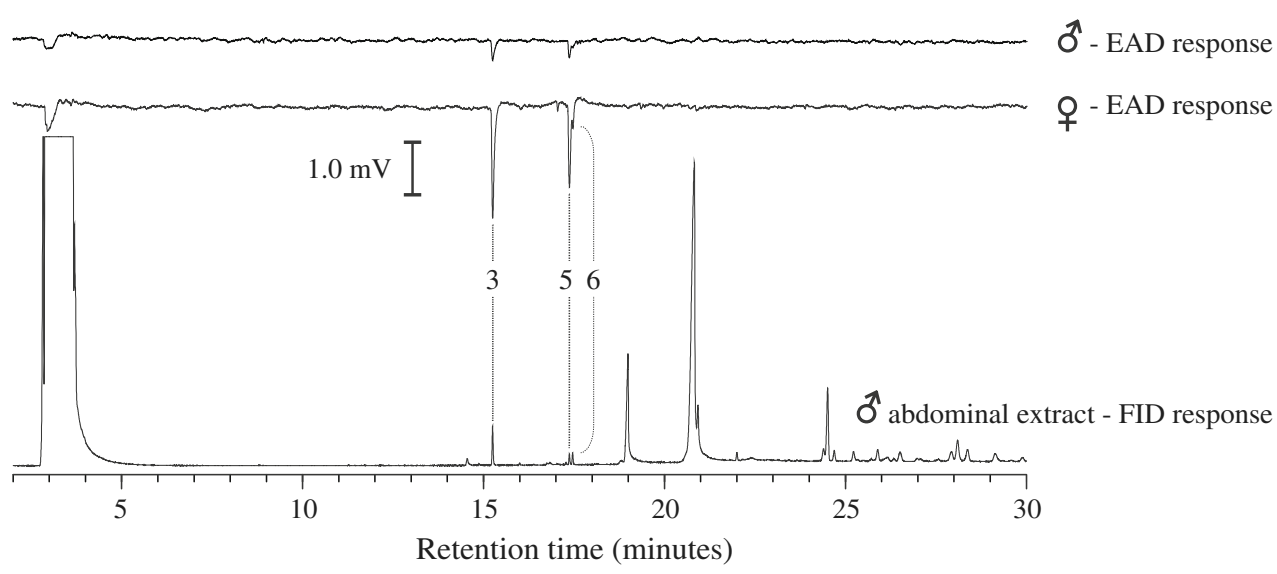


Fig. 3 Responses of male and female Dermestes haemorrhoidalis antennae to conspecific male headspace extract (AT-5 column); (1) unknown, (3) isopropyl dodecanoate, (4) isopropyl tridecanoate, (5) isopropyl (Z)-9-tetradecenoate,

(6) isopropyl tetradecanoate, (9) unknown
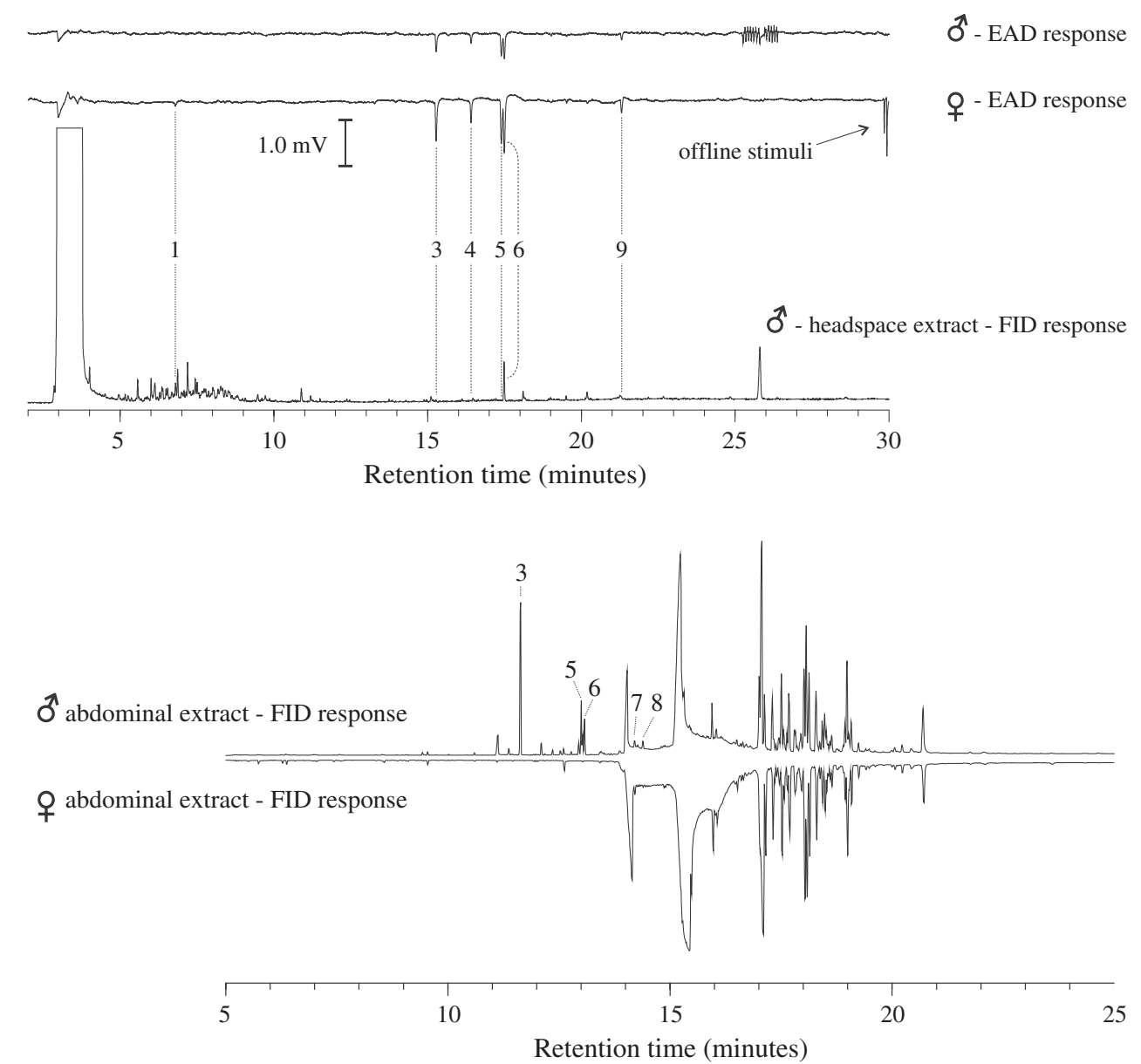

Retention time (minutes)
Fig. 4 GC-MS total ion count profile of male and female Dermestes haemorrhoidalis abdominal extracts (AT-5 column); (3) isopropyl dodecanoate, (5) isopropyl (Z)-9-tetradecenoate,

(6) isopropyl tetradecanoate,

(7) isopropyl (Z)-

9-hexadecenoate, (8) isopropyl hexadecanoate hexadecanoate (8) (Fig. 4). The isopropyl esters were found exclusively in male abdominal extracts and not in the corresponding abdominal extracts of female beetles. Peaks were identified based on spectral similarity and comparison of their Kovats indices with synthetic standards on both polar AT-aquawax and apolar AT-5 columns (Table 1). The position and configuration of the double bonds in the monounsaturated isopropyl esters were determined by DMDS derivatisation and subsequent analysis of the methylthio derivatives (Vincenti et al. 1987; Griepink et al. 1996; Attygalle 1998).

Analysis of male D. haemorrhoidalis headspace volatiles revealed the presence of (3), (5) and (6) which compounds were also found in the abdominal extract. A very minute EAD-active peak corresponding to isopropyl (Z)-9-dodecenoate (3) was observed in the headspace extract on a polar aquawax column, but its presence could not be confirmed with GC-MS. In addition, another EADactive compound (1) was observed in all GC-EAD measurements. When examining the same time window (based on Kovats indices) with GC-MS, only peaks with typical spectra of methyl- and ethyl-benzenes showed up. Different benzene type compounds, viz. 1,2,3-trimethyl benzene,
Table 1 Retention indices (Kovats indices) of EAD-active compounds of Dermestes haemorrhoidalis Kuster beetles and head space extracts

\begin{tabular}{lcl}
\hline Compound name & \multicolumn{2}{c}{ Kovats index (column type) } \\
\cline { 2 - 3 } & AT-5 & AT-Aquawax \\
\hline Unknown 1 & 994 & 1381 \\
Isopropyl (Z)-9-dodecenoate (2) & 1625 & 1865 \\
Isopropyl dodecanoate (3) & 1625 & 1814 \\
Isopropyl tridecanoate (4) & 1726 & 1917 \\
Isopropyl (Z)-9-tetradecenoate (5) & 1814 & 2054 \\
Isopropyl tetradecanoate (6) & 1822 & 2018 \\
Isopropyl (Z)-9-hexadecenoate (7) & 2014 & 2248 \\
Isopropyl hexadecanoate (8) & 2028 & 2222 \\
Unknown 9 & 2214 & 2434 \\
\hline
\end{tabular}

1,3,5-trimethyl benzene, 2-ethyl-1-hexanol and phenol were tested for their EAD responses in antenna of both sexes but none of them elicited a EAD response. Small GC-EAD responses in male and female antennae were observed in headspace extracts corresponding to isopropyl tridecanoate (4). A later eluting GC-EAD active compound 
Table 2 Bioassay (Petridish) of male and female Dermestes haemorrhoidalis to conspecific body extracts and synthetic reference compounds $(0.5 \mu \mathrm{g} /$ compound) ( 30 beetles in each replication; 3 replications)

Means followed by same letters are not significantly different by DMRT, $P<0.05$

\begin{tabular}{|c|c|c|c|c|c|}
\hline \multirow[t]{2}{*}{ Treatment } & \multirow[t]{2}{*}{ Tested sample } & \multicolumn{2}{|c|}{$\begin{array}{l}\% \text { D. haemorrhoidalis } \\
\text { adults aroused } \\
(5 \mathrm{~min})\end{array}$} & \multicolumn{2}{|c|}{$\begin{array}{l}\% \text { D. haemorrhoidalis adults } \\
\text { touched the central paper } \\
\text { disc }(30 \mathrm{~min})\end{array}$} \\
\hline & & Male & Female & Male & Female \\
\hline 1. & Male beetle extract & $73.33 \mathrm{e}$ & $71.11 \mathrm{~g}$ & $44.44 \mathrm{~g}$ & $47.77 \mathrm{e}$ \\
\hline 2. & Female beetle extract & $12.22 \mathrm{~b}$ & $8.88 \mathrm{~b}$ & $4.44 \mathrm{bc}$ & $1.11 \mathrm{a}$ \\
\hline 3. & Isopropyl (Z)-9-dodecenoate (2) & $42.22 \mathrm{~d}$ & $14.44 \mathrm{c}$ & $21.10 \mathrm{e}$ & $8.88 \mathrm{c}$ \\
\hline 4. & Isopropyl dodecanoate (3) & $36.66 \mathrm{~d}$ & $19.99 \mathrm{~d}$ & $15.55 \mathrm{~d}$ & $19.99 \mathrm{~d}$ \\
\hline 5. & Isopropyl tridecanoate (4) & $1.11 \mathrm{a}$ & $1.11 \mathrm{a}$ & $1.11 \mathrm{a}$ & $1.11 \mathrm{a}$ \\
\hline 6. & Isopropyl (Z)-9-tetradecenoate (5) & $31.10 \mathrm{c}$ & $11.11 b c$ & $21.10 \mathrm{e}$ & $7.77 \mathrm{bc}$ \\
\hline 7. & Isopropyl tetradecanoate (6) & $11.11 \mathrm{~b}$ & $21.10 \mathrm{~d}$ & $1.11 \mathrm{a}$ & $1.11 \mathrm{a}$ \\
\hline 8. & Isopropyl (Z)-9-hexadecenoate (7) & $1.11 \mathrm{a}$ & $2.22 \mathrm{a}$ & $1.11 \mathrm{a}$ & $1.11 \mathrm{a}$ \\
\hline 9. & Isopropyl hexadecanoate (8) & $1.11 \mathrm{a}$ & $1.11 \mathrm{a}$ & $1.11 \mathrm{a}$ & $1.11 \mathrm{a}$ \\
\hline 10. & Treatment $3+4$ & $37.77 \mathrm{~d}$ & $34.44 \mathrm{e}$ & $23.33 \mathrm{e}$ & $22.21 \mathrm{~d}$ \\
\hline 11. & Treatment $6+7$ & $42.22 \mathrm{~d}$ & $39.99 \mathrm{f}$ & $28.88 \mathrm{f}$ & $23.33 \mathrm{~d}$ \\
\hline 12. & Treatment $8+9$ & $1.11 \mathrm{a}$ & $1.11 \mathrm{a}$ & $1.11 \mathrm{a}$ & $1.11 \mathrm{a}$ \\
\hline 13. & Treatment $5+10+11$ & $9.99 b$ & $9.99 b$ & $6.66 c$ & $5.55 \mathrm{~b}$ \\
\hline \multirow[t]{2}{*}{14.} & Control (hexane) & $1.11 \mathrm{a}$ & $1.11 \mathrm{a}$ & $3.33 \mathrm{~b}$ & $1.11 \mathrm{a}$ \\
\hline & SEM \pm & 1.413 & 1.638 & 1.493 & 1.333 \\
\hline
\end{tabular}

(9) could not be detected by GC-MS and as a consequence could not be unambiguously identified.

Bioassays of extracts and synthetics

Laboratory Petri dish bioassays revealed that male D. haemorrhoidalis abdominal extract significantly aroused and attracted both sexes compared to a female abdominal extract (Table 2). Of the synthetic compounds tested, treatments with compounds (2), (3), (5) and (6) either pure or mixed showed significant behavioural reactions compared to other treatments $(P<0.05)$. Approximately $70 \%$ of the males and females showed an 'arousal response' and half of the beetles touched the central paper disc impregnated with $D$. haemorrhoidalis male extract. Pure compounds, viz. (7) and (8), and mixtures thereof did not evoke any significant behavioural responses. Compound (4) alone did not evoke a significant behavioural reaction as well, although it was found to be EAD active. Interestingly, addition of this compound to mixtures containing compounds (2)-(3) and (5)-(6) inhibited the arousal or attraction in these bioassays.

\section{Discussion}

In spite of its economic importance in storage of food stuff and animal feeds worldwide, no information other than the studies of Levinson et al. (1978) are available pertaining online electrophysiological studies with regard to D. haemorrhoidalis in particular, and to the genus
Dermestes in general. The present study suggests that adult male $D$. haemorrhoidalis abdominal extract contains compounds (3), (5) and (6) capable of producing high olfactory receptor potential as well as behavioural changes in both sexes. The female $D$. haemorrhoidalis extract does not produce any response either in conspecific female or male antennae indicating that these three compounds are exclusively conserved in males. Based on the high receptor potentials of female antennae to the compounds described, it is obvious that female antenna are more sensitive and are believed to have highly developed receptors in its sensilla compared to its conspecific counterpart.

Males of $D$. haemorrhoidalis beetle possess one gland on each on the third and fourth abdominal sternite with an exogenous pore surrounded by 6-8 bristles, whereas such glands and structures are absent in females. These exocrine glands have been found also in males of other Dermestes species (Levinson et al. 1978; Imai et al. 1990). The abdominal extracts of male $D$. haemorrhoidalis elicits, arouses and attracts its conspecific males and females in Petri dish bioassays, indicating the presence of an aggregation pheromone in the male abdominal extracts. The three identified isopropyl esters, viz. (3), (5), (6), and the unidentified compounds (1) and (9) are believed to play an important role in chemical communication among them. Compounds (7) and (8) have been found in male abdominal extract but did not elicit any EAD response, whereas their synthetic standards in higher concentrations could only evoke very minute receptor potentials in the order of 0.01 and $0.04 \mathrm{mV}$, respectively. 
Female antennae of $D$. haemorrhoidalis beetles appear much more sensitive to male headspace volatiles and antennae of both sexes produce higher receptor responses to compound (5) when compared to compound (6) (Fig. 2). In male headspace volatile extracts, however, the concentration of compound (6) is higher than compound (5) and GC-EAD responses are about the same (Fig. 3). This would suggest that the insect is more sensitive to the unsaturated isopropyl (Z)-9-tetradecenoate (5) when compared to the saturated isomer. EAD peaks (2) and (3) co-elute on apolar column like the AT-5 column used in this research. Their identification has been consolidated by changing from apolar AT-5 to a polar wax type column. On the wax column, the saturated $\mathrm{C}_{12}$ compound (3) elutes before its unsaturated isomer (2). The reaction of $(E)$ - and $(Z)$-monounsaturated pheromones with DMDS proceeds stereospecific, yielding each one unique DMDS-adduct which are easily separated using GC (Attygalle 1998). Therefore, the (Z)-conformation for all identified unsaturated isopropyl carboxylates could be unambiguously appointed due to their clear difference in GC retention time when compared to the (reference) (E)-DMDS adducts. The EAD-active peaks 1 and 9 could not be identified due to the fact that with GC-MS, no EAD-active peaks could be detected in the expected time frame where EAD activity has been determined with GC-EAD. However, in case of compound (9), comparison of the Kovats indices with those of the identified isopropyl esters (Table 1) suggests that compound (9) could well have been isopropyl octadecenoate. This has not been further examined. Another EADactive peak which elutes between $\mathrm{C}_{12}$ and $\mathrm{C}_{14}$ isopropyl carboxylate esters in the male headspace volatiles has been identified as isopropyl tridecanoate (4). The fact that we could not detect this compound in the extracts cannot be explained other than that this compound is produced only from living and active male beetles. Our reference isopropyl tridecanoate (4) has been synthesized only after we already had identified this compound, therefore contamination can be excluded. Francke et al. (1979), Levinson et al. (1978) reported that 11 males produced isopropyl carboxylates occurring in the pheromone blend of D. maculatus of which compound (2) elicited high receptor potentials in male D. maculatus antenna. Our results indicate that this compound is also EAD active in both the antenna of D. haemorrhoidalis. The present studies also reveal the differences in perception of the compounds by the antenna of male and female D. haemorrhoidalis. It is significant to note that isopropyl (Z)-9-dodecenoate (2) has been detected neither in male nor in female extracts or headspace volatiles, whereas synthetic (2) produces strong electrophysiological responses comparable to those of the identified compounds. It is presumed that this compound is an important pheromone compound in Dermestes species in general. Evolutionarily, this compound is probably not used by $D$. haemorrhoidalis anymore, but still this insect is able to respond electrophysiologically, perhaps to be able to avoid related species of Dermestes.

Female $D$. maculatus extracts appear not to be attractive to conspecific females (Shaaya 1981) similar to our observation with D. haemorrhoidalis. However, other behavioural studies indicate that $D$. maculatus possesses a male-produced aggregation pheromone as well as a femaleproduced sex pheromone (Shaaya 1981; Rakoswki and Cymborowski 1986; Jaskulska et al. 1987). Our Petri dish bioassays also suggest the presence of a male-produced aggregation pheromone, since male abdominal extracts attract significant numbers of males and females rather than abdominal extracts of female $D$. haemorrhoidalis.

Therefore, it is concluded that males of D. haemorrhoidalis dominate the females in terms of pheromone production. Compounds (3), (5), (6) produced in male abdominal glands present on the abdominal sternum are all physiologically and behaviourally active to both the sexes. Compound (4) which has been detected in male head space volatiles only, did not show any behavioural response in bioassays on its own except for being EAD active. The electrophysiologically active unidentified compounds (1) and (9) are not tested in the behaviour assays. Although not every compound that is electrophysiologically active will stimulate behavioural responses in the insect (Blatt et al. 1998), it is most likely that the unidentified compounds play an essential role in the behaviour of this species. Compounds (2), (3), (5), (6) have elicited significant behavioural changes in male and female beetles thus making these compounds possible aggregation pheromone candidates. A compound like isopropyl (Z)-9-dodecenoate (2), although not detected in any extracts of D. haemorrhoidalis, could perhaps be applied as repellent or as sexual masking agent. Because isopropyl tridecanoate (4) diminishes the response of $D$. haemorrhoidalis when combined with other potential aggregation pheromone candidates, this compound may have potential as a mating disruptant.

Acknowledgments The present work has been carried out at PHEROBANK laboratories, Plant Research International (PRI), Wageningen University and Research, Wageningen, The Netherlands, under the Award of Biotechnology Overseas Associateship (Long Term), Department of Biotechnology (DBT), Ministry of Science and Technology, Government of India, New Delhi, to the senior author. Thanks are due to Dr S. Edison, Director, Central Tuber Crops Research Institute (ICAR), Trivandrum, India, for granting deputation to the first author. Thanks are due to Mr. Leo Poleij of PRI PHEROBANK laboratories for synthesis of the synthetic standards; Mr. Henk Swarts of PRI PHEROBANK laboratories for setting up the automated headspace collection unit and Mr. Peter van Deventer of PRI for collection of the insects.

Open Access This article is distributed under the terms of the Creative Commons Attribution Noncommercial License which 
permits any noncommercial use, distribution, and reproduction in any medium, provided the original author(s) and source are credited.

\section{References}

Abdel Kader MM, Barak AV (1979) Evidence for a sex pheromone in the hide beetle, Dermestes maculatus (De Geer) (Coleoptera: Dermestidae). J Chem Ecol 5:805-813

Adams RG (1980) Dermestes leechi Kalik in stored products and new diagnostic characters for Dermestes spp. (Coleoptera: Dermestidae). J Stored Prod Res 16:119-122

Adams RG (1990) Dermestes leechi Kalik (Coleoptera: Dermestidae) from an Egyptian mummy. Entomol Gaz 41:119-120

Attygalle AB (1998) Microchemical techniques. In: Millar JG, Haynes KF (eds) Methods in chemical ecology, vol 1. Kluwer, Massachusetts, pp 207-294

Axtell RC, Arends JJ (1990) Ecology and management of arthropod pests of poultry. Annu Rev Entomol 35:101-126

Blatt SE, Borden JH, Pierce HD Jr, Gries R, Gries G (1998) Alarm pheromone system of the western conifer seed bug Leptoglossus occidentalis. J Chem Ecol 24:1013-1031

Cloud JA, Collison CH (1986) Comparison of various poultry house litter components for hide beetle (Dermestes maculatus DeGeer) larval development in the laboratory. Poult Sci 65:1911-1914

Francke W, Levinson AR, Jen TL, Levinson HZ (1979) Isopropyl carboxylates-a new class of insect pheromones. Angew Chem Int Ed Engl 18:796-797

Geden CJ, Hogsette JA (2001) Research and extension needs for integrated pest management for Arthropods of veterinary importance. Proceedings of a workshop in Lincoln, Nebraska, 12-14 April 1994, Center for medical, agricultural, and veterinary entomology USDA-ARS, Gainesville, Florida (last updated, October 2001)

Greenberg B, Wells JD (1998) Forensic use of Megaselia abdita and M. scalaris (Phoridae: Diptera): case studies, development rates, and egg structure. J Med Entomol 35:205-209

Griepink FC, Van Beek TA, Posthumus MA, De Groot A, Visser JH, Voerman S (1996) Identification of the sex pheromone of Scrobipalpula absoluta: determination of double bond positions in triple unsaturated straight chain molecules by means of dimethyl disulphide derivatization. Tetrahedron Lett 37:411-414

Hava J, Votruba P (2005) New distributional data about Dermestidae (Coleoptera) and description of a new species from Sudan. Ann Hist Nat Musei Natl Hung 97:41-49

Imai TI, Kodama H, Mori M, Kohno M (1990) Morphological and chemical studies of male abdominal exocrine glands of the black larder beetle, Dermestes ater De Geer (Coleoptera: Dermestidae). Appl Entomol Zool 25:113-118

Jacob TA, Fleming DA (1984) The effect of temperature and humidity on the egg period, larval instars and oviposition of Dermestes haemorrhoidalis Kuster (Coleoptera: Dermestidae). Entomol Mon Mag 120:131-137

Jaskulska B, Rakowski G, Cymborowski B (1987) The effect of juvenile hormone on aggregative behaviour of Dermestes maculatus. Biochem Physiol 87A:771-773

Levinson A, Levinson H (1995) Reflections on structure and function of pheromone glands in storage insect species. Anz Schadlingskd Pfl 68:99-118

Levinson HZ, Levinson AR, Jen TI, Williams JLD, Kahn G, Francke W (1978) Production site, partial composition and olfactory perception of a pheromone in the male hide beetle. Naturwiss $65: 543-545$
Levinson AR, Levinson HZ, Francke W (1981) Intraspecific attractants of the hide beetle Dermestes maculatus (De Geer). Mitt Dtsch Ges Allg Angew Ent 2:235-237

Linnie MJ, Keatinge MJ (2000) Pest control in museums: toxicity of para-dichlorobenzene, 'vapona'TM, and naphthalene against all stages in the life-cycle of museum pests, Dermestes maculatus Degeer, and Anthrenus verbasci (L.) (Coleoptera: Dermestidae). Int Biodeteter Biodegr 45:1-13

Nair SM (1986) Biodeterioration of museum collections by dermestid beetles, with particular reference to tropical countries. In: Barry S, Houghton DR (eds) Biodeterioration 6. Papers presented at the 6th international biodeterioration symposium, Washington, DC, August 1984, pp 337-343

Panzani RC, Ariano R (2001) Arthropods and invertebrates allergy (with the exclusion of mites): the concept of panallergy. Allergy $56: 1-22$

Rakowski G (1988) Effect of illumination intensity on the response of the hide beetle, Dermestes maculatus, to aggregation pheromone. J Insect Physiol 34:1101-1104

Rakowski G, Cymborowski B (1986) Some environmental influences and physiological factors influencing the response of the hide beetle, Dermestes maculatus, to aggregation pheromone. Int $\mathrm{J}$ Invert Reprod Dev 9:35-41

Rakowski G, Sterzycki R, Cymborowski B (1981) Analysis of aggregative behaviour of Dermestes maculatus DeGeer. In: Sehnal F, Zabza A, Menn JJ, Cymborowski B (eds) Regulation of insect development and behaviour. Technical University of Wroclaw, Wroclaw, p 885

Ramachandran S, Hern J, Almeyda J, Main J, Patel KS (1997) Contact dermatitis with cervical lymphadenopathy following exposure to the hide beetle, Dermestes peruvianus. Brit J Dermatol 136:943-945

Rustin MHA, Munro DD (1984) Popular urticaria caused by Dermestes maculatus Degeer. Clin Exp Dermatol 9:317-321

Sagvolden BA, Hansen LO (2001) Notes on Norwegian Coleoptera 5. Norw J Entomol 48:281-287

Sahaf KA (2007) Studies on Dermestes maculatus Degeer (Coleoptera: Dermestidae), a pest of stored silk cocoons of silkworm, Bombyx mori L. J Entomol Res 31:163-164

Schroeder H, Klotzbach H, Oesterhelweg L, Puschel K (2002) Larder beetles (Coleoptera, Dermestidae) as an accelerating factor for decomposition of a human corpse. Forensic Sci Int 127:231-236

Shaaya E (1981) Sex pheromone of Dermestes maculatus DeGeer (Coleoptera, Dermestidae). J Stored Prod Res 17:13-16

Stafford KC, Collison CH, Burg JG, Cloud JA (1988) Distribution and monitoring lesser mealworms, hide beetles, and other fauna in high-rise, caged-layer poultry houses. J Agric Entomol 5:89-101

Steffan JR (1982) The insects found in the mummy of Ramases II. Ann Soc Entomol Fr 18:531-537

Sukontason K, Narongchai P, Kanchai C, Vichairat K, Sribanditmongkol P, Bhoopat T, Kurahashi H, Chockjamsai M, Piangjai S, Bunchu N, Vongvivach S, Samai W, Chaiwong T, Methanitikorn R, Ngern-Klun R, Sripakdee D, Boonsriwong W, Siriwattanarungsee S, Srimuangwong C, Hanterdsith B, Chaiwan K, Srisuwan C, Upakut S, Moopayak K, Vogtsberger RC, Olson JK (2007) Forensic entomology cases in Thailand: a review of cases from 2000 to 2006. Parasitol Res 101:1417-1423

Takeda T, Watanabe H, Kitahar T (1997) Direct oxidation of acetals and aldehydes to esters. Synlett 10:1149-1150

Vick KW, Burkholder WE, Gorman J (1970) Interspecific response to sex pheromones of Trogoderma species (Coleoptera: Dermestidae). Ann Entomol Soc Am 63:379-381

Vincenti M, Guglielmetti G, Cassani G, Tonini C (1987) Determination of double bond position in diunsaturated compounds by mass spectrometry of dimethyl disulfide derivatives. Anal Chem 59:694-699 